\title{
Assessing the Severity of Perinatal Hypoxia-Ischemia in Piglets Using Near-Infrared Spectroscopy to Measure the Cerebral Metabolic Rate of Oxygen
}

\author{
KENNETH M. TICHAUER, DAISY Y. L. WONG, JENNIFER A. HADWAY, R. JANE RYLETT, TING-YIM LEE, \\ AND KEITH ST. LAWRENCE
}

\author{
Imaging Division [K.M.T., J.A.H., T.-Y.L., K.S.L.], Lawson Health Research Institute, London, Ontario, Canada, N6A 4V2, Canada; \\ Department of Medical Biophysics [K.M.T., T.-Y.L., K.S.L.], Department of Physiology and Pharmacology [D.Y.L.W., R.J.R.], University \\ of Western Ontario, London, Ontario, N6A 5C1, Canada; Molecular Brain Research Group [D.Y.L.W., R.J.R.], Imaging Research \\ Laboratories [J.A.H., T.-Y.L., K.S.L.], Robarts Research Institute, London, Ontario, N6A 5C1, Canada
}

\begin{abstract}
Reduced cerebral function after neonatal hypoxiaischemia is an early indicator of hypoxic-ischemic encephalopathy. Near-infrared spectroscopy offers a clinically relevant means of detecting impaired cerebral metabolism from the measurement of the cerebral metabolic rate of oxygen $\left(\mathrm{CMRO}_{2}\right)$. The purpose of this study was to determine the relationship between postinsult $\mathrm{CMRO}_{2}$ and duration of hypoxia-ischemia in piglets. Twelve piglets were subjected to randomly selected durations of hypoxia-ischemia (5-28 min) and five animals served as controls. Measurements of $\mathrm{CMRO}_{2}$ were taken before and for $24 \mathrm{~h}$ after hypoxia-ischemia. Histology was carried out in nine piglets (six insults, three controls) to estimate brain injury. In the first $4 \mathrm{~h}$ after the insult, average $\mathrm{CMRO}_{2}$ of the insult group was significantly depressed $(33 \pm 3 \%$ reduction compared with controls) and by $8 \mathrm{~h}$, a significant correlation developed, which persisted for the remainder of the study, between $\mathrm{CMRO}_{2}$ and the duration of ischemia. Histologic staining suggested little brain damage resulted from shorter insult durations and considerable damage from more prolonged insults. This study demonstrated that near-infrared spectroscopy could detect early changes in $\mathrm{CMRO}_{2}$ after hypoxia-ischemia for a range of insult severities and $\mathrm{CMRO}_{2}$ could be used to distinguish insult severity by $8 \mathrm{~h}$ after the insult. (Pediatr Res 65: 301-306, 2009)
\end{abstract}

$\mathrm{P}$ erinatal hypoxia-ischemia continues to be a significant cause of neurodevelopmental impairment and disability in the term infant. Results from animal and newborn human studies suggest a significant portion of hypoxic-ischemic brain damage can be delayed by $6-72 \mathrm{~h}$ after resuscitation (1). Long-term outcome could be improved if mechanisms leading to delayed cell death could be suppressed during the latent period between insult and injury-a period termed the "therapeutic window" (2). The exact duration of the therapeutic window is unknown; however, the success rate of treatment strategies depends on early administration. Unfortunately, the clinical signs of perinatal hypoxia-ischemia can be subtle and there are as yet no proven methods capable of reliably and

Received August 18, 2008; accepted September 24, 2008.

Correspondence: Kenneth M. Tichauer, Ph.D., Imaging Division, Lawson Health Research Institute, 268 Grosvenor St., London, Ontario N6A 4V2, Canada; e-mail: ktichaue@lawsonimaging.ca

This work was supported by Canadian Institutes of Health Research (CIHR). accurately assessing the severity of injury within the confines of the therapeutic window (2).

For nearly $30 \mathrm{y}$ it has been known that cerebral ischemia can cause long-term depression of cerebral metabolism despite resuscitation (3). Studies conducted in neonatal lambs demonstrated that a reduction in cerebral energy metabolism can be seen within $4 \mathrm{~h}$ after resuscitation from hypoxiaischemia $(4,5)$ and metabolic impairment has been similarly observed in newborns within $18 \mathrm{~h}$ of birth by proton magnetic resonance spectroscopy (6), while delayed energy failure, as quantified by phosphorous magnetic resonance spectroscopy, can be used to predict neurologic outcome (7). The results of these studies suggest that a noninvasive measure of the cerebral metabolic rate of oxygen $\left(\mathrm{CMRO}_{2}\right)$ may be of particular interest to the clinical prognosis of hypoxia-ischemia.

Recent technical advances have made near-infrared spectroscopy (NIRS) a promising tool for assessing brain function at the bedside of critically ill newborns. With continuouswave, broadband-spectrum NIRS, the absolute concentration of cerebral deoxy- $\mathrm{Hb}([\mathrm{HHb}])$ (8) and cerebral blood flow (CBF) (9) can be accurately determined. By combining these measurements, we have developed a NIRS system capable of rapidly measuring $\mathrm{CMRO}_{2}$ and have validated it in newborn piglets over a range of metabolic states $(10,11)$.

The NIRS measurement of $\mathrm{CMRO}_{2}$ was also validated in a study that monitored piglets for $6 \mathrm{~h}$ after resuscitation from 30 min of hypoxia-ischemia (12). An immediate and persistent $25 \%$ reduction in $\mathrm{CMRO}_{2}$ was observed after the insult, suggesting NIRS has promise as an indicator of hypoxiaischemia within the therapeutic window. However, the sensitivity of the NIRS measurement to insult severity was not investigated. The purpose of the present study was to grade the duration of hypoxia-ischemia in piglets to determine the relationship between posthypoxia-ischemia measures of $\mathrm{CMRO}_{2}$ and insult severity, as quantified by the duration of ischemia.

Abbreviations: CBF, cerebral blood flow; CBV, cerebral blood volume; $\mathrm{CMRO}_{2}$, cerebral metabolic rate of oxygen; $\mathrm{FIO}_{2}$, fraction of inspired oxygen; HHb, deoxy-hemoglobin; ICG, indocyanine green; NIRS, near-infrared spectroscopy; MAP, mean arterial pressure; OEF, oxygen extraction fraction 


\section{MATERIALS AND METHODS}

Animal preparation. The study was approved by the Animal Use Subcommittee of the Canadian Council on Animal Care at the University of Western Ontario. Newborn Duroc piglets $(n=17)$ were delivered from a local supplier on the morning of the experiment. Anesthesia was induced and surgery was conducted using $3 \%$ isoflurane. The surgical procedure has been presented in detail elsewhere (12). Briefly, piglets were tracheotomized and mechanically ventilated. Vascular occluders (In Vivo Metric, Healdsberg, CA) were placed around both carotid arteries just proximal to the carotid bifurcation. Catheters were inserted into an ear and an abdominal vein for injection of the NIRS-sensitive, intravascular contrast agent indocyanine green (ICG) and for glucose infusion, respectively. Another catheter was inserted into a femoral artery for continuous monitoring of blood pressure and for collection of arterial blood samples for gas and glucose determinations. Isoflurane was reduced to $1.75 \%$ after surgery and maintained for the entire experiment.

Experimental procedures. The piglets were randomly divided into two groups: an insult group $(n=12)$ and a sham-operated control group $(n=5)$. After $1 \mathrm{~h}$ of baseline, hypoxia/carotid occlusion was induced in insult-group piglets by clamping both carotid arteries and reducing the fraction of inspired oxygen $\left(\mathrm{FIO}_{2}\right)$ to $7 \%$. The carotid clamps were released and $\mathrm{FIO}_{2}$ was returned to baseline after a randomly selected duration (10-30 $\mathrm{min})$. The duration of ischemia, which is not the same as the duration of occlusion due to the possibility of collateral blood flow to the brain, was defined as the amount of time the mean arterial pressure (MAP) was less than $70 \%$ of baseline during the insult (13). CBF was measured at the point when the MAP fell to $70 \%$ of baseline to ensure the occurrence of ischemia. $\mathrm{CMRO}_{2}, \mathrm{CBF}$, cerebral blood volume $(\mathrm{CBV}),[\mathrm{HHb}]$, and oxygen extraction fraction $(\mathrm{OEF})$ were measured with NIRS $(10,11)$ three times during baseline at intervals of $20 \mathrm{~min}$ and then at $1,4,8,12,16,20$, and $24 \mathrm{~h}$ after resuscitation from hypoxia-ischemia. At $24 \mathrm{~h}$, piglets were euthanized. In 9 of the 17 piglets (6 insult piglets, 3 controls), brains were harvested to look for early histologic evidence of neuronal injury using Fluoro-Jade B staining.

At all times during the experiment (excluding the insult), arterial $\mathrm{PCO}_{2}$ was maintained between $4.7-5.3 \mathrm{kPa}$ by adjusting the respiratory rate, whereas arterial $\mathrm{PO}_{2}$ was maintained at $13-24 \mathrm{kPa}$ by adjusting the ratio of oxygen to medical air. Blood glucose was kept between 3 and $8 \mathrm{mM}$ by constant infusion of a $25 \%$ dextrose solution into a belly vein. A water-heating blanket was used to maintain a rectal temperature between 37.5 and $38.5^{\circ} \mathrm{C}$. Arterial $\mathrm{pH}, \mathrm{MAP}$, and heart rate were also monitored.

Near-infrared spectroscopy. NIRS data were collected with a continuouswave, broadband (600-980 nm) system with a single emission fiberoptic bundle and a single detection bundle (9). The bundles were placed $3 \mathrm{~cm}$ apart, parasagittally on the head, proximal to the widest part of the brain.

The method used to calculate $\mathrm{CMRO}_{2}$ with NIRS, which was designed to be clinically applicable, has been discussed in detail previously (10). Briefly, measurements of $\mathrm{CMRO}_{2}$ were based on the Fick principle:

$$
\mathrm{CMRO}_{2}=\mathrm{CBF}\left(\left[\mathrm{O}_{2}\right]_{a}-\left[\mathrm{O}_{2}\right]_{v}\right)
$$

The oxygen concentration of the arteries feeding the cerebral tissue $\left(\left[\mathrm{O}_{2}\right]_{a}\right)$ was determined using a pulse oximeter from a front foot of the piglet. Measurements of $[\mathrm{HHb}]$ were quantified using the second-derivative technique (8) and used to indirectly determine the oxygen concentration of the vessels draining the cerebral tissue $\left(\left[\mathrm{O}_{2}\right]_{v}\right)$. The calculation of CBF and CBV required an i.v., $0.1 \mathrm{mg} / \mathrm{kg}$ bolus injection of ICG and relied on deconvolution of the subsequent arterial and tissue concentration-time curves of the tracer (9). The fraction of oxygen extracted from arterial blood into the brain, OEF, was also calculated.

Fluoro-Jade B staining. To represent the region interrogated by the NIRS probes, coronal tissue slices were cut from the widest part of the brain and paraffin-embedded. Six sections were then cut at a thickness of $5 \mu \mathrm{m}$. The sections were stained with Fluoro-Jade B to assess the amount of neuronal degeneration (14). Slides were viewed with a fluorescence microscope at $20 \times$ magnification. Positive cells were then counted manually on digital images from eight cortical regions (four in each hemisphere) and two regions from the hippocampus (one in each hemisphere) by an observer blinded to treatment. The original selection of the regions was arbitrary but corresponding regions were selected for all slices and all piglets. Three replicate sections from each region for each piglet were stained and counted separately, with data averaged to yield the number of positive cells per area, per animal. At least one control section was included in each batch of staining as a standard with which to ensure the quality of the procedure.

Statistical analysis. The statistical software package, SPSS 16.0 (SPSS, Chicago, IL), was used for all statistical analyses. Repeated-measures, twoway mixed analysis of variances (ANOVAs) were used to compare measure- ments between control and insult groups, with time as the within-subjects variable. The analyses were conducted for all physiologic parameters, CBF, $\mathrm{CBV}, \mathrm{OEF}, \mathrm{CMRO}_{2}$, and [HHb]. For parameters in which a two-way, time-by-group effect was revealed by the omnibus test, group differences at individual time points were uncovered by one-way ANOVA with Bonferroni correction to account for multiple comparisons. Linear regressions were used for all data from the insult-group piglets at each time point to uncover correlations with respect to the duration of ischemia. Statistical significance for all tests was based on a $p<0.05$. All data are presented as mean \pm SEM.

\section{RESULTS}

Average age and weight of the seventeen piglets were $18.9 \pm 11.5 \mathrm{~h}$ and $1.6 \pm 0.2 \mathrm{~kg}$. Table 1 summarizes the results of the physiologic parameters for insult and control groups before hypoxia-ischemia and during early and late reperfusion periods (statistics, however, were done without temporal averaging). There were no significant differences between the insult group and the controls for any other physiologic parameter at any time point. Heart rate tended to increase over time in both groups; however, the trend was not significant and the values remained within a normal physiologic range. For insult-group piglets, no statistically significant correlations were found when linear regressions were conducted between each physiologic parameter and the duration of ischemia at any point of the experiment.

Figure 1 illustrates the average results of the NIRS measurements, specifically $\mathrm{CMRO}_{2}, \mathrm{CBF}, \mathrm{CBV}, \mathrm{OEF}$, and [HHb] from the insult and control groups at 1, 4, 8, 12, 16, 20, and $24 \mathrm{~h}$ after the termination of hypoxia-ischemia. Repeatedmeasures ANOVA revealed a significant between-subjects interaction for the postinsult $\mathrm{CMRO}_{2}$ data $\left[F_{1,15}=23.5, p<\right.$ 0.001 , Power $>0.99$ ]. Further analysis uncovered that at 1,4 , 8,12 , and $24 \mathrm{~h}$ after the insult, average $\mathrm{CMRO}_{2}$ of the insult group was significantly lower than controls $(p<0.05)$. No significant time-by-group interactions were observed for CBF, CBV, or OEF postinsult. There was, however, a weak timeby-group interaction for $[\mathrm{HHb}]\left[F_{6,90}=2.84, p<0.05\right.$, Power $>0.6]$. The source of this interaction was a significantly lower $[\mathrm{HHb}]$ in the insult group compared with controls at $20 \mathrm{~h}$ after

Table 1. Physiologic parameters

\begin{tabular}{lccc}
\hline & Baseline & $\mathrm{R} 1$ & $\mathrm{R} 2$ \\
\hline Arterial $\mathrm{PCO}_{2}(\mathrm{kPa})$ & & & \\
$\quad$ Insult & $5.4 \pm 0.2$ & $5.1 \pm 0.1$ & $5.1 \pm 0.2$ \\
$\quad$ Control & $5.2 \pm 0.1$ & $5.2 \pm 0.1$ & $4.9 \pm 0.2$ \\
Mean arterial & & & \\
$\quad$ pressure $(\mathrm{kPa})$ & & & \\
$\quad$ Insult & $6.6 \pm 0.2$ & $6.2 \pm 0.2$ & $6.7 \pm 0.3$ \\
$\quad$ Control & $7.4 \pm 0.6$ & $6.7 \pm 0.7$ & $7.3 \pm 0.5$ \\
Arterial pH & & & \\
$\quad$ Insult & $7.41 \pm 0.02$ & $7.43 \pm 0.02$ & $7.46 \pm 0.01$ \\
$\quad$ Control & $7.45 \pm 0.01$ & $7.45 \pm 0.01$ & $7.47 \pm 0.01$ \\
Glucose $(\mathrm{mmol} / \mathrm{L})$ & & & \\
$\quad$ Insult & $5.2 \pm 0.7$ & $5.6 \pm 0.6$ & $4.8 \pm 0.6$ \\
$\quad$ Control & $5.0 \pm 0.7$ & $5.2 \pm 0.7$ & $4.3 \pm 0.6$ \\
Heart rate $\left(\mathrm{min}^{-1}\right)$ & & & \\
$\quad$ Insult & $148 \pm 4$ & $173 \pm 7$ & $175 \pm 8$ \\
Control & $146 \pm 11$ & $171 \pm 11$ & $168 \pm 11$ \\
\hline
\end{tabular}

Values from the hypoxia-ischemia group $(n=12)$ and the control group $(n=5)$ at baseline, during the early reperfusion period (R1-average of 1, 4, and $8 \mathrm{~h}$ postinsult) and during the late reperfusion period (R2-average of 12 , 16,20 , and $24 \mathrm{~h}$ postinsult). Values are mean \pm SEM. 

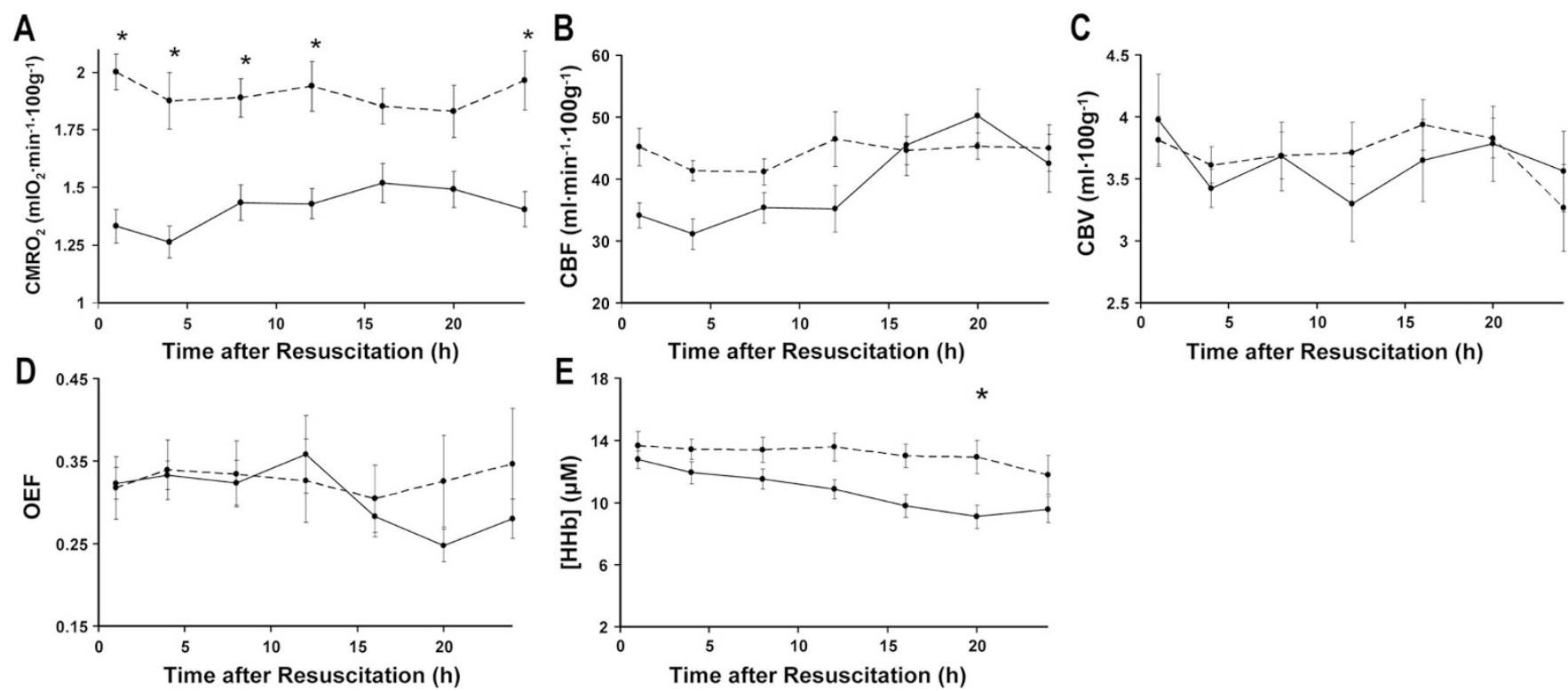

Time after Resuscitation (h)

Figure 1. Cerebral metabolic rate of oxygen $\left(\mathrm{CMRO}_{2}\right)$, cerebral blood flow $(\mathrm{CBF})$, cerebral blood volume $(\mathrm{CBV})$, oxygen extraction fraction $(\mathrm{OEF})$, and cerebral concentration of deoxy- $\mathrm{Hb}([\mathrm{HHb}])$ of control and insult-group piglets after hypoxia-ischemia. Average $\mathrm{CMRO}_{2}(A), \mathrm{CBF}(B), \mathrm{CBV}(C), \mathrm{OEF}(D)$, and $[\mathrm{HHb}]$ $(E)$, after the termination of hypoxia-ischemia for control (dashed line; $n=5$ ) and insult (solid line; $n=12$ ) groups. *Control and insult groups significantly different from each other $(p<0.05)$. Error bars are SEM.

hypoxia-ischemia $(p<0.05)$. Furthermore, there were no significant differences between baseline measures from controls and baseline measures from insult-group piglets or postmock insult measures from controls at any time for any variable. Baseline $\mathrm{CMRO}_{2}, \mathrm{CBF}, \mathrm{CBV}$, and $\mathrm{OEF}$ were $1.9 \pm$ $0.1 \mathrm{~mL} \mathrm{O}_{2} \cdot \mathrm{min}^{-1} \cdot 100 \mathrm{~g}^{-1}, 46.6 \pm 2.2 \mathrm{~mL} \cdot \mathrm{min}^{-1} \cdot 100$ $\mathrm{g}^{-1}, 3.9 \pm 0.1 \mathrm{~mL} \cdot 100 \mathrm{~g}^{-1}$, and $0.31 \pm 0.02$, respectively.

Table 2 presents the duration of hypoxia/occlusion and the duration of ischemia for each of the 12 insult-group piglets. Three piglets were exposed to $10 \mathrm{~min}$ of hypoxia/carotid occlusion, 1 piglet to $15 \mathrm{~min}, 3$ piglets to $20 \mathrm{~min}$, and 5 piglets

Table 2. Characterization of the insult

\begin{tabular}{ccccc}
\hline Piglet & $\begin{array}{c}\text { Duration of } \\
\text { hypoxia- } \\
\text { occlusion } \\
(\mathrm{min})\end{array}$ & $\begin{array}{c}\text { Duration of } \\
\text { hypoxia-only } \\
(\mathrm{min})\end{array}$ & $\begin{array}{c}\text { Duration of } \\
\text { hypoxia- } \\
\text { ischemia } \\
(\mathrm{min})\end{array}$ & $\begin{array}{c}\text { Cerebral blood } \\
\text { flow at ischemia } \\
\left(\mathrm{mL} \cdot \mathrm{min}^{-1} \cdot 100 \mathrm{~g}^{-1}\right)\end{array}$ \\
\hline 1 & 10 & 2 & 8 & $\mathrm{NA}$ \\
2 & 10 & 5 & 5 & 3.5 \\
3 & 10 & 5 & 5 & 12.1 \\
4 & 15 & 9 & 6 & 3.4 \\
5 & 20 & 5 & 15 & 14.8 \\
6 & 20 & 14 & 6 & 14.2 \\
7 & 20 & 15 & 5 & NA \\
8 & 30 & 2 & 28 & 7.1 \\
9 & 30 & 2 & 28 & 1.8 \\
10 & 30 & 10 & 20 & 2.2 \\
11 & 30 & 10 & 20 & NA \\
12 & 30 & 15 & 15 & 3.9 \\
\hline
\end{tabular}

Individual characterizations of the insult duration are presented. Hypoxiaocclusion is the duration of hypoxia and bicarotid occlusion. Hypoxia-only is the duration of hypoxia-occlusion when the mean arterial pressure was higher than $70 \%$ of baseline. Hypoxia-ischemia is the duration of hypoxia-occlusion when the mean arterial pressure was lower than $70 \%$ of baseline. Cerebral blood flow at ischemia is the measurement made when the mean arterial pressure reach $70 \%$ of baseline during hypoxia-occlusion. NA represents missing data when it was not possible to accurately calculation cerebral blood flow. to $30 \mathrm{~min}$. Within the first minutes of hypoxia/occlusion, average MAP increased to $9.1 \pm 0.8 \mathrm{kPa}$ before crashing. The median duration of hypoxia/occlusion while MAP remained above $70 \%$ was $7 \mathrm{~min}$ (range, $2-15 \mathrm{~min}$ ). CBF was calculated during this period in three piglets with an average of $32.5 \pm$ $5.0 \mathrm{~mL} \cdot \min ^{-1} \cdot 100 \mathrm{~g}^{-1}$. After the initial period of hypertension, all piglets became hypotensive and MAP remained depressed for the remainder of the insult. The median duration of hypotension was $11.5 \mathrm{~min}$ (range, 5-28 min). CBF was successfully calculated at the onset of hypotension in 9 of the 12 insult-group piglets and the average was $7.1 \pm 1.8$ $\mathrm{mL} \cdot \min ^{-1} \cdot 100 \mathrm{~g}^{-1}$.

Table 3 summarizes the temporal aspects of the relationship between postinsult $\mathrm{CMRO}_{2}$ and duration of ischemia. At 1 and $4 \mathrm{~h}$ postinsult, the regression between $\mathrm{CMRO}_{2}$ and duration of ischemia was not statistically significant. A significant regression was reached at $8 \mathrm{~h}$ postinsult and the magnitude of the slope, as well as the $R$ value of the correlations, increased sequentially at 12 and $16 \mathrm{~h}$, reaching a plateau by $20 \mathrm{~h}$

Table 3. Correlations between cerebral metabolic rate of oxygen $\left(\mathrm{CMRO}_{2}\right)$ and duration of ischemia

\begin{tabular}{ccc}
\hline Time postinsult $(\mathrm{h})$ & Slope of correlation & $r$ value of correlation \\
\hline 1 & -0.002 & 0.08 \\
4 & -0.007 & 0.27 \\
8 & -0.019 & $0.64^{*}$ \\
12 & -0.018 & $0.73^{*}$ \\
16 & -0.028 & $0.86^{*}$ \\
20 & -0.027 & $0.91^{*}$ \\
24 & -0.025 & $0.84^{*}$ \\
\hline
\end{tabular}

Slopes and $r$-values for correlations between duration of ischemia and $\mathrm{CMRO}_{2}$ measurements collected after hypoxia-ischemia in all insult-group piglets $(n=12)$. The units for the slope are $\mathrm{mL} \mathrm{O}_{2} \cdot \min ^{-1} \cdot 100 \mathrm{~g}^{-1} \cdot \min$ of insult $^{-1}$. Values are mean \pm SEM.

$* p<0.05$. 

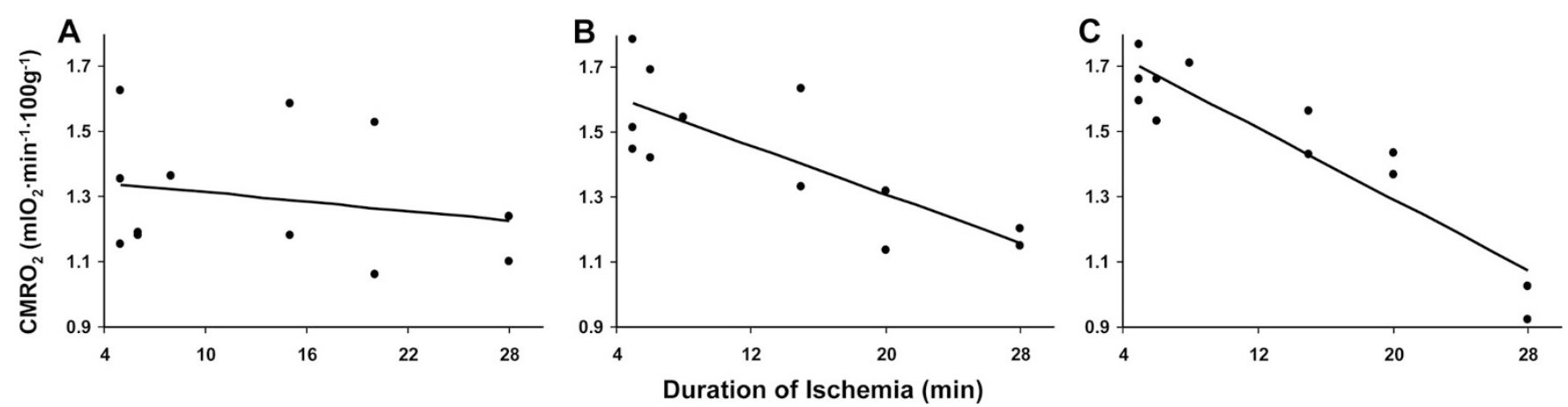

Figure 2. Correlation between the cerebral metabolic rate of oxygen $\left(\mathrm{CMRO}_{2}\right)$ and duration of ischemia during early, middle and late reperfusion. The $\mathrm{CMRO}$ of insult-group piglets $(n=12)$ averaged over 1 and $4 \mathrm{~h}$ postinsult $(A), 8$ and $12 \mathrm{~h}$ postinsult $(B)$, and 16,20 , and $24 \mathrm{~h}$ postinsult $(C)$, plotted against duration of ischemia. Solid lines indicate fits of regression (for $A$ : slope $=-0.005 \mathrm{~mL} \mathrm{O}_{2} \cdot \mathrm{min}^{-1} \cdot 100 \mathrm{~g}^{-1} \cdot \min$ of insult ${ }^{-1}, r=0.22$, NS, for $B$ : slope $=-0.019 \mathrm{~mL}$ $\mathrm{O}_{2} \cdot \min ^{-1} \cdot 100 \mathrm{~g}^{-1} \cdot \min$ of insult ${ }^{-1}, r=0.78, p<0.05$ and for $C$ : slope $=-0.027 \mathrm{~mL} \mathrm{O}_{2} \cdot \min ^{-1} \cdot 100 \mathrm{~g}^{-1} \cdot \min$ of insult ${ }^{-1}, r=0.92, p<0.05$ ).
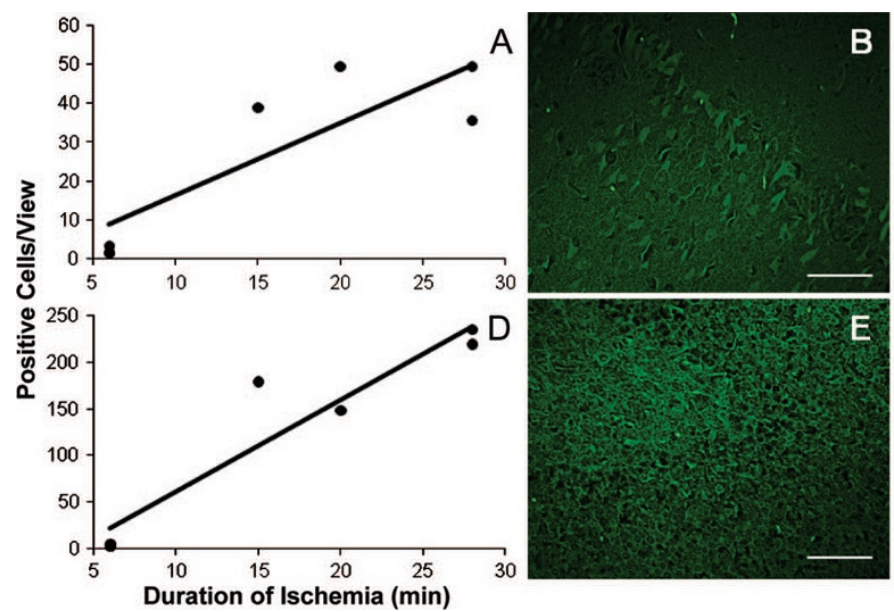

postinsult. These correlations are illustrated in Figure 2. Figure $2 A-C$ present individual $\mathrm{CMRO}_{2}$ values from all insultgroup piglets averaged over early ( 1 and $4 \mathrm{~h})$, mid ( 8 and $12 \mathrm{~h}$ ), and late $(16,20$, and $24 \mathrm{~h})$ reperfusion periods, respectively, plotted against the duration of ischemia. Linear regression of all other NIRS measurements compared with the duration of ischemia yielded no statistically significant correlations at any time point except for [HHb], which demonstrated a correlation at $20 \mathrm{~h}$ postinsult $(r=0.80$, slope $=-2.7$ $\mu \mathrm{M}$ per min of insult, $p<0.05$ ).

Figure 3 presents the average number of Fluoro-Jade Bpositive cells in cortical and hippocampal regions of six insultgroup piglet brains plotted against duration of ischemia. Examples of Fluoro-Jade B stains from the cerebral cortex and hippocampus of one severely injured animal and one control animal are also presented. In both the cortex and the hippocampus, the number of Fluoro-Jade B-positive cells demonstrated statistically significant correlations with insult duration ( $r=0.85, p<0.05$ and $r=0.94, p<0.05$, respectively). The average number of Fluoro-Jade B-positive cells in the cerebral cortex and the hippocampus from control animals was $3.8 \pm 0.5$ and $2.9 \pm 0.4$, respectively.

\section{DISCUSSION}

The delay between cerebral hypoxia-ischemia and brain injury in the newborn has led to the idea that diagnosis and

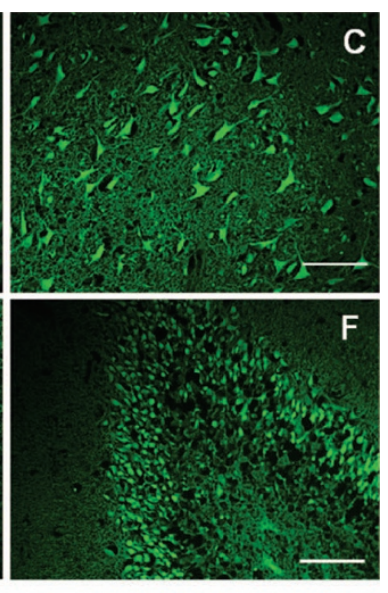

Figure 3. Histology. Figure $(A)$ presents the average number of Fluoro Jade B-positive cells in the cortex of six piglets subjected to varying durations of hypoxiaischemia plotted against duration of ischemia, coupled with corresponding images from a control animal $(B)$ and a severe animal $(C)$. Figure $(D)$ presents the average number of Fluoro Jade B-positive cells in the hippocampus plotted against duration of ischemia, coupled with corresponding images from a control animal $(E)$ and a severe animal $(F)$. The scale bars in each photomicrograph indicate $100 \mu \mathrm{m}$. treatment of hypoxia-ischemia during early reperfusion could improve long-term neurologic outcome. In general, current clinical methods of diagnosing the occurrence of a hypoxicischemic event have proven to suffer from poor specificity (15); consequently, there remains a demand for novel diagnostic schemes. Reduced cerebral energy metabolism has shown promise as an early indicator of hypoxia-ischemia $(4,5)$; however, traditional methods for measuring cerebral energy metabolism are poorly suited for neonates. Recently, a robust NIRS method for safely and accurately measuring cerebral oxidative metabolism was developed in our laboratory and validated over a range of metabolic states and after hypoxic-ischemic injury in the piglet (10-12). The purpose of the present study was to test the hypothesis that an early measure of $\mathrm{CMRO}_{2}$ after hypoxia-ischemia-acquired with the described NIRS technique-can be used as an indicator of the severity of insult incurred.

Similar approaches for measuring $\mathrm{CMRO}_{2}$ have been published that have used oxy-Hb as an endogenous blood flow indicator after a rapid change in $\mathrm{FIO}_{2}(16)$. The main advantage with the present technique is the increased precision of the CBF measurements gained by using ICG as a tracer (17). The precision was further increased (to less than 10\%) by using a deconvolution method designed to account for variable arrival times to calculate CBF, which allowed data outside of the first pass of the bolus to be included, and also allowed CBV to be 
calculated (9). Although ICG is approved for use in newborns in North America, there is some risk: the incidence of systemic allergic reactions to the dye has been reported as approximately $1: 250,000$ in adults and newborns (18). Recently, however, a hypoallergenic form of ICG, infracyanine (SERB Laboratories, Paris, France), has been developed.

The present study demonstrated that the $\mathrm{CMRO}_{2}$ response after hypoxia-ischemia could be used to distinguish hypoxicischemic piglets (over a range of severities) from controls. In the early stages after resuscitation, there were no significant correlations when the $\mathrm{CMRO}_{2}$ of insult-group piglets was compared with the duration of ischemia; however, as a group, the average $\mathrm{CMRO}_{2}$ of the insult piglets was significantly lower than that of controls. Subsequently, the $\mathrm{CMRO}_{2}$ of piglets that were subjected to shorter durations of ischemia was found to gradually return toward control levels, whereas the $\mathrm{CMRO}_{2}$ of piglets that were subjected to longer durations of ischemia remained depressed. This was evident by the emergence of a significant correlation between postinsult $\mathrm{CMRO}_{2}$ and duration of ischemia (Table 3) and the gradual increase of mean insult-group $\mathrm{CMRO}_{2}$ (Fig. 1).

Of the parameters used to calculate $\mathrm{CMRO}_{2}$-namely $\mathrm{CBF}$, $\mathrm{CBV}$ and $[\mathrm{HHb}]$, only [HHb] revealed any statistically significant group differences after hypoxia-ischemia. Specifically, average $[\mathrm{HHb}$ ] was reduced in the insult group compared with controls at $20 \mathrm{~h}$ after the insult. Also at the $20 \mathrm{~h}$ mark, the $[\mathrm{HHb}]$ of the insult-group piglets had a statistically significant correlation with the duration of ischemia $(p<0.05)$. However, the fact that there was only a significant difference at one time point - in addition to the results of Peeters-Scholte et al., (19) who found no change in [HHb] from baseline out to $24 \mathrm{~h}$ after severe hypoxia-ischemia in piglets_refutes the idea of using $[\mathrm{HHb}]$ in a prognostic capacity. In a previous study from our group, $\mathrm{CMRO}_{2}$ was monitored for $6 \mathrm{~h}$ after resuscitation in piglets subjected to $30 \mathrm{~min}$ of hypoxia-ischemia (12); in support of the results from the present study, even though hypoxia-ischemia caused a significant and persistent $25 \%$ reduction in $\mathrm{CMRO}_{2}$, there were no group effects with the parameters used to determine $\mathrm{CMRO}_{2}$. The insensitivity of these parameters to hypoxia-ischemia highlights the importance of measuring $\mathrm{CMRO}_{2}$ for diagnostic purposes.

$\mathrm{CBF}$ tended to be lower in insult-group piglets than controls in the first $4 \mathrm{~h}$ after resuscitation although the between-groups effect was not statistically significant. Reduced CBF, combined with reduced $\mathrm{CMRO}_{2}$, has been observed after hypoxiaischemia in the neonatal lamb (5). Under normal conditions, $\mathrm{CBF}$ and $\mathrm{CMRO}_{2}$ are tightly coupled and if $\mathrm{CMRO}_{2}$ was observed to drop by approximately $30 \%$, as seen in the present study, a similar drop would be expected in CBF. The apparent lack in sensitivity of early $\mathrm{CBF}$ measurements to insult duration and the complete inability to use CBF to discern between groups late in the experiment is possibly linked to a hypoxiaischemia-induced loss of autoregulation, and subsequent uncoupling from metabolism (20).

Despite clamping of both carotid arteries during the insult, some piglets may be able to maintain adequate $\mathrm{CBF}$ by increasing flow to collateral vertebral arteries (21). The CBF measurements in the early insult window acquired from three piglets confirmed that relatively normal levels of CBF could be maintained despite bicarotid occlusion due to retaliatory hypertension. It is known that hypoxia alone is not nearly as severe as the combination of both hypoxia and ischemia (22); therefore, to ensure an accurate representation of the duration of ischemia for each piglet, the starting time of the insult was defined as the point when MAP dropped below $70 \%$ of baseline (13). This threshold is the lower limit of autoregulation, beyond which, CBF becomes pressure-dependent and, therefore, any collateral flow would drop. The decision to use the $70 \%$ MAP threshold is further reinforced by the results of CBF measurements made at the onset of hypotension, which demonstrated that blood flow had reached ischemic levels $\left(<15 \mathrm{~mL} \cdot \min ^{-1} \cdot 100 \mathrm{~g}^{-1}\right)$. Furthermore, in a previous study we found that the average $\mathrm{CBF}$ during hypoxia/occlusion was $36 \pm 6 \mathrm{~mL} \cdot \mathrm{min}^{-1} \cdot 100 \mathrm{~g}^{-1}$ when MAP was greater than $70 \%$ of baseline and $8 \pm 3 \mathrm{~mL} \cdot \min ^{-1} \cdot 100 \mathrm{~g}^{-1}$ when MAP was less than $70 \%$ (12). The duration of hypoxia without ischemia is not considered to be a large contributor to brain injury in this study since the maximum duration of hypoxia alone was only $15 \mathrm{~min}$ (Table 2).

The amount of Fluro-Jade B positive staining also correlated with the defined duration of ischemia however the $n$ size was too small for the data to be conclusive. Fluoro-Jade B was chosen because it provides an early indication of neuronal degeneration with a high signal-to-noise ratio (14) and the purpose of its use was to assess the extent of brain damage resulting from a range of ischemic durations. The results suggested that durations of ischemia of 15 min or greater resulted in considerable injury to the cortex and hippocampus whereas shorter durations of ischemia (two piglets exposed to 5 min of hypoxia-ischemia) resulted in a quantity of staining similar to controls brains, which showed no signs of pathology. Correspondingly, the $\mathrm{CMRO}_{2}$ of these two piglets with shorter durations of ischemia returned to within $1 \mathrm{SD}$ of control levels by $8 \mathrm{~h}$ of reperfusion. It is possible, however, that the damage in these piglets may have been delayed so that it was not detected at $24 \mathrm{~h}$. Studies are ongoing to address these limitations by conducting experiments with a $72 \mathrm{~h}$ postinsult recovery period and with a focus on mild to moderate injuries, which are arguably more difficult to detect clinically.

The importance of early prognosis warrants further discussion regarding the effects of hypoxia-ischemia on $\mathrm{CMRO}_{2}$ in the first hours after reperfusion. The results of the present study suggest that $\mathrm{CMRO}_{2}$ is very sensitive to hypoxiaischemia during this window, regardless of the duration of ischemia since the average $\mathrm{CMRO}_{2}$ of all insult-group piglets was $33 \pm 3 \%$ lower than that of control piglets; however, there was no significant correlation between $\mathrm{CMRO}_{2}$ of insultgroup piglets and duration of ischemia until $8 \mathrm{~h}$ postinsult. Hypoxia-ischemia has been shown to trigger long-term depression of cerebral metabolism in both adult $(3,23)$ and neonatal $(4,5)$ animal models. Interestingly, this depression has been observed despite a restitution of high-energy metabolites in awake rats that showed exploratory behavior and recovery of motor functions (23). Potential causes of the postischemic cerebral depression observed in this study include the prolonged effect of a release of adenosine, which 
occurs during hypoxia and ischemia and acts by inhibiting synaptic activity (24); mitochondrial dysfunction, caused by either ischemic damage or inhibition by the postischemic release of nitric oxide (25); or perhaps an increased sensitivity to the anesthetic agent, isoflurane, which could have caused an increase in mean alveolar concentration and possibly a reduction in synaptic activity that would have reduced metabolic demand (26).

Because of the limitations of this study, it is not possible to comment conclusively on the exact mechanism for the postischemic cerebral depression. If the effect was related to the use of isoflurane, it is feasible that the correlation between $\mathrm{CMRO}_{2}$ and the duration of ischemia observed at $8 \mathrm{~h}$ postinsult emerged as the increased sensitivity to isoflurane abated. In general, infants suspected of sustaining a hypoxic-ischemic insult are not anesthetized; therefore, it is possible that the sensitivity of $\mathrm{CMRO}_{2}$ to insult severity will occur much earlier after resuscitation clinically, creating a potential for prognosis of insult severity with NIRS during early reperfusion. Furthermore, the greater energy demand of the infant compared with the anesthetized piglet could increase the sensitivity of the NIRS measurement by widening the difference between $\mathrm{CMRO}_{2}$ of healthy and injured patients. In piglets, awake levels of $\mathrm{CMRO}_{2}$ are roughly $30 \%$ higher than levels under isoflurane in piglets (11). Studies are continuing in our laboratory to explore the relationship between $\mathrm{CMRO}_{2}$ and insult severity during early reperfusion using a combination of fentanyl and nitrous oxide for anesthesia. This combination has been demonstrated to have little effect on cerebral metabolism (27).

To the best of the authors' knowledge, this is the first study to find a relationship between $\mathrm{CMRO}_{2}$ and hypoxic-ischemic insult severity. Furthermore, $\mathrm{CMRO}_{2}$ was measured using a NIRS apparatus designed for rapid and repeated use at the bedside, strengthening the proposal that NIRS may be an effective tool for prognosis and treatment planning of hypoxicischemic encephalopathy in critically ill newborns.

\section{REFERENCES}

1. Sunshine P 2002 Hypoxic-ischemic encephalopathy: pathophysiology and implications for therapy. Przegl Lek 59:6-9

2. du Plessis AJ, Volpe JJ 2002 Perinatal brain injury in the preterm and term newborn. Curr Opin Neurol 15:151-157

3. Sims NR, Zaidan E 1995 Biochemical changes associated with selective neuronal death following short-term cerebral ischaemia. Int J Biochem Cell Biol 27:531-550

4. Thorngren-Jerneck K, Ley D, Hellstrom-Westas L, Hernandez-Andrade E, Lingman G, Ohlsson T, Oskarsson G, Pesonen E, Sandell A, Strand SE, Werner O, Marsal K
2001 Reduced postnatal cerebral glucose metabolism measured by PET after asphyxia in near term fetal lambs. J Neurosci Res 66:844-850

5. Rosenberg AA 1986 Cerebral blood flow and $\mathrm{O}_{2}$ metabolism after asphyxia in neonatal lambs. Pediatr Res 20:778-782

6. Hanrahan JD, Cox IJ, Azzopardi D, Cowan FM, Sargentoni J, Bell JD, Bryant DJ, Edwards AD 1999 Relation between proton magnetic resonance spectroscopy within 18 hours of birth asphyxia and neurodevelopment at 1 year of age. Dev Med Child Neurol 41:76-82

7. Martin E, Buchli R, Ritter S, Schmid R, Largo RH, Boltshauser E, Fanconi S, Duc $\mathrm{G}$, Rumpel H 1996 Diagnostic and prognostic value of cerebral ${ }^{31} \mathrm{P}$ magnetic resonance spectroscopy in neonates with perinatal asphyxia. Pediatr Res 40:749-758

8. Matcher SJ, Cope M, Delpy DT 1994 Use of the water absorption spectrum to quantify tissue chromophore concentration changes in near-infrared spectroscopy. Phys Med Biol 39:177-196

9. Brown DW, Picot PA, Naeini JG, Springett R, Delpy DT, Lee TY 2002 Quantitative near infrared spectroscopy measurement of cerebral hemodynamics in newborn piglets. Pediatr Res 51:564-570

10. Brown DW, Hadway J, Lee TY 2003 Near-infrared spectroscopy measurement of oxygen extraction fraction and cerebral metabolic rate of oxygen in newborn piglets. Pediatr Res 54:861-867

11. Tichauer KM, Hadway JA, Lee TY, St Lawrence K 2006 Measurement of cerebral oxidative metabolism with near-infrared spectroscopy: a validation study. J Cereb Blood Flow Metab 26:722-730

12. Tichauer KM, Brown DW, Hadway J, Lee TY, St Lawrence K 2006 Near-infrared spectroscopy measurements of cerebral blood flow and oxygen consumption following hypoxia-ischemia in newborn piglets. J Appl Physiol 100:850-857

13. Foster KA, Colditz PB, Lingwood BE, Burke C, Dunster KR, Roberts MS 2001 An improved survival model of hypoxia/ischaemia in the piglet suitable for neuroprotection studies. Brain Res 919:122-131

14. Schmued LC, Hopkins KJ 2000 Fluoro-Jade B: a high affinity fluorescent marker for the localization of neuronal degeneration. Brain Res 874:123-130

15. Volpe JJ 2001 Neurology of the Newborn. Philadelphia: W.B. Saunders Company

16. Yoxall CW, Weindling AM 1998 Measurement of cerebral oxygen consumption in the human neonate using near infrared spectroscopy: cerebral oxygen consumption increases with advancing gestational age. Pediatr Res 44:283-290

17. Patel J, Marks K, Roberts I, Azzopardi D, Edwards AD 1998 Measurement of cerebral blood flow in newborn infants using near infrared spectroscopy with indocyanine green. Pediatr Res 43:34-39

18. Garski TR, Staller BJ, Hepner G, Banka VS, Finney RA Jr 1978 Adverse reactions after administration of indocyanine green. JAMA 240:635

19. Peeters-Scholte C, van den Tweel E, Ioroi T, Post I, Braun K, Veldhuis W, Nicolay $\mathrm{K}$, Groenendaal F, van Bel F 2002 Pharmacological interventions in the newborn piglet in the first $24 \mathrm{~h}$ after hypoxia-ischemia. A hemodynamic and electrophysiological perspective. Exp Brain Res 147:200-208

20. Lou HC, Lassen NA, Tweed WA, Johnson G, Jones M, Palahniuk RJ 1979 Pressure passive cerebral blood flow and breakdown of the blood-brain barrier in experimental fetal asphyxia. Acta Paediatr Scand 68:57-63

21. Munkeby BH, Lyng K, Froen JF, Winther-Larssen EH, Rosland JH, Smith HJ, Saugstad OD, Bjornerud A 2004 Morphological and hemodynamic magnetic resonance assessment of early neonatal brain injury in a piglet model. J Magn Reson Imaging 20:8-15

22. Rice JE III, Vannucci RC, Brierley JB 1981 The influence of immaturity on hypoxic-ischemic brain damage in the rat. Ann Neurol 9:131-141

23. Kozuka M, Smith ML, Siesjo BK 1989 Preischemic hyperglycemia enhances postischemic depression of cerebral metabolic rate. J Cereb Blood Flow Metab 9:478-490

24. Martin ED, Fernandez M, Perea G, Pascual O, Haydon PG, Araque A, Cena V 2007 Adenosine released by astrocytes contributes to hypoxia-induced modulation of synaptic transmission. Glia 55:36-45

25. Hagberg H 2004 Mitochondrial impairment in the developing brain after hypoxiaischemia. J Bioenerg Biomembr 36:369-373

26. Rampil IJ, Weiskopf RB, Brown JG, Eger EI II, Johnson BH, Holmes MA, Donegan JH 1988 I653 and isoflurane produce similar dose-related changes in the electroencephalogram of pigs. Anesthesiology 69:298-302

27. Yaster M, Koehler RC, Traystman RJ 1994 Interaction of fentanyl and nitrous oxide on peripheral and cerebral hemodynamics in newborn lambs. Anesthesiology 80:364-371 